\title{
Rehacer cuerpos, construir identidades. La piel que habito (Pedro Almodóvar, 2011) y Tarántula (Thierry Jonquet, 1984)
}

\author{
Remake Bodies, Build Identities. \\ La piel que habito (Pedro Almodóvar, 2011) and \\ Tarántula (Thierry Jonquet, 1984)
}

\author{
CARMEn PeÑa ARdid \\ Universidad de Zaragoza \\ cpardid@unizar.es \\ ORCID ID: 0000-0001-9824-5281
}

\begin{abstract}
Resumen: Este estudio profundiza en la relación de La piel que habito (2011) con la novela Tarántula (1984) de Thierry Jonquet, principal fuente de inspiración del filme de Pedro Amodóvar, para observar tanto sus vínculos como la transformación creativa a la que el cineasta manchego somete el material literario en diálogo fecundo con otros referentes artísticos. Esta perspectiva de análisis -atenta a la configuración narrativa del filme- saca a la luz el personal enfoque que adopta Almodóvar respecto al tema de la identidad de género, a su relación con el cuerpo y la orientación sexual, desbordando la propuesta epistemológica tanto de la novela como de los esquemas míticos tradicionales.
\end{abstract}

Palabras clave: Cine y literatura; identidad de género; mitos clásicos; cuerpo; Almodóvar; Jonquet.

\begin{abstract}
This study aims to go deeper into the relationship between the film La piel que habito (2011) and the novel Tarántula (1984) by Thierry Jonquet, which is the main source of inspiration for Pedro Almodovar's film, in order to analyze both the common links and the creative transformation that the Manchego film maker develops from the literary source in a fruitful dialogue with other artistic models. This analysis perspective - paying special attention to the narrative framework of the film- focuses on the personal approach adopted by Almodovar as regards the subject of gender identity and its ties with the physical body and sexual orientation, which goes way beyond the epistemic views that can be found in the novel and in the traditional mythical estructures.
\end{abstract}

Key words: Cinema and literatura; gender identity; classical myths; body; Almodóvar; Jonquet. 


\section{Carmen Peña Ardid}

Hay una fantasía flotando, tenaz, en nuestra cultura desde hace siglos: la de que el hombre creó a la mujer. Y otra aún más osada, que procede de ella: la de que el hombre produce criaturas femeninas más hermosas y mejores que las mujeres, con las que puede sustituir a éstas con ventaja para lo bueno y para lo malo, para el amor sublime y para la paliza mortal.

(Pilar Pedraza, Máquinas de amar)

La contrasexualidad no es la creación de una nueva naturaleza, sino más bien el fin de la Naturaleza como orden que legitima la sujeción de unos cuerpos a otros.

(Beatriz Preciado, Manifiesto contrasexual)

\section{LA TRADICIÓN QUE HABITAMOS}

La piel que habito es un excelente ejemplo de cómo el fenómeno de la adaptación de una obra literaria al cine involucra muchas veces modelos y referentes artísticos que, más allá de la fuente literaria de partida, funcionan como hipotextos complementarios o referencias indispensables para la creación del nuevo texto (Fernández, 2003: 58-59; Peña Ardid, 2014: 205). Esta película de Pedro Almodóvar se inspira en una violenta novela negra -Mygale (Tarántula, 1984)- del escritor francés Thierry Jonquet. Sin embargo, desde su presentación pública en el Festival de Cannes de 2011, se destacaron la diversidad de géneros por los que el filme transita -el melodrama familiar, el cine de anticipación científica, el terror psicológico, el thriller de suspense ${ }^{1}-$ y los múltiples lazos que, aparte de Mygale, entabla con un gran número de obras cinematográficas, literarias, pictóricas o musicales, en una complejísima «operación de transtextualidad» (Poyato Sánchez, 2015: 284) nada insólita, por otra parte, en la creación de Almodóvar y acorde «con la manera habilidosa como este autor aglutina en su discurso motivos procedentes de la cultura alta y popular, contemporánea y tradicional demostrando una capacidad innata de poner en relación lo viejo con lo nuevo» (Aronica, 2005: 58).

La trama de La piel que habito reactualiza o revisita, con la mediación de otros textos, dos mitos ampliamente recreados en la cultura occidental: el de Pigmalión y el de Prometeo-Frankenstein (Almodóvar, 2012: 161$163)^{2}$. El arquetipo del mad doctor revive en los experimentos con terapia

\footnotetext{
${ }^{1}$ Véase el prólogo de Vicente Molina Foix al guion de la película (2012: 7-12) y Zurian (2013: 263).

${ }^{2}$ Una de las mejores síntesis que he encontrado de la trama de La piel que habito procede de un comentario, sin firma, de internet que venía a formular esta pregunta: «¿Qué significa que un genio maligno intente resucitar a su esposa infiel
} 
transgénica que realiza el cirujano plástico Robert Ledgard, cuyo referente cinematográfico más directo se encuentra en Los ojos sin rostro (Les yeux sans visage, Georges Franju, 1960), un clásico del cine de terror europeo, inspirado en la novela homónima de Jean Redon (1959), con el que La piel que habito comparte el problema de la reconstrucción de un rostro quemado por medios nada éticos, el simbolismo del trasplante quirúrgico de la piel o la escenografía ambiental de la casa-clínica de los doctores protagonistas (Poyato Sánchez, 2015: 291-292; Zecchi, 2015: 47-48; Sánchez Noriega, 2017: 375). Por otro lado, en el empeño del doctor Ledgard de reproducir el rostro de su esposa muerta en otro ser humano al que convierte en el doble de su fetiche están las huellas -pero también la transgresión del objeto de deseo- de Vértigo (Alfred Hitchcock, 1959), a la vez que sus manipulaciones sobre el cuerpo de un maniquí que se transmuta en el cuerpo real de Vicente/Vera han recordado al Archibaldo de la Cruz de Ensayo de un crimen (1955), de Luis Buñuel, a cuya película Tristana (1970) se rinde, por otra parte, un homenaje explícito en la imagen panorámica de Toledo con la que comienza La piel que habito ${ }^{3}$.

$\mathrm{Y}$ en este «juego de correspondencias con la memoria del cine» (Poyato Sánchez, 2015: 291), otro tipo de diálogo -que transgrede algunos de los esquemas sobre el binarismo de género de la tradición anterior- es el que se establece con películas que han abordado expresamente aspectos sombríos de la experiencia transexual, como la de R. W. Fassbinder, Un año con trece lunas (In einem Jahr mit 13 Monden, 1978) (Morata, 2017), o con filmes anteriores de Almodóvar que han incorporado a su universo memorables personajes transexuales - La ley del deseo (1987), Todo sobre mi madre (1999), La mala educación (2004)- o han tratado situaciones de violencia ligadas al deseo masculino heterosexual

en el cuerpo forzadamente transexualizado del hombre que violó a su hija?». Es una historia -de restitución, venganza y metamorfosis- digna de figurar en Las metamorfosis de Ovidio. Pero el resumen no agota del todo los conflictos de la película. La piel que habito también es la historia de cómo la "víctima" (Vicente/Vera) descubre su culpa y la causa del gran daño que sufre, se sobrepone al sometimiento y afronta un cambio físico de identidad sexual.

${ }^{3}$ El modo en que se aproxima la cámara a la finca "El Cigarral", traspasando la verja de entrada y la ventana también enrejada que da acceso a la habitación en la que se encuentra Vera ha recordado justamente el comienzo de Citizen Kane (Orson Welles, 1941) (Dargis, 2011). Pedro Almodóvar ha desvelado, por otra parte, muchos de los referentes de su película: «Una historia de estas características me hacía pensar en Luis Buñuel, Alfred Hitchcock, todos los Fritz Lang (desde el gótico al noir). Pensé también en la estética pop del terror de la Hammer o en el más psicodélico y kitsch del giallo italiano...» (2012: 154-155). Reminiscencias de Fantomas (la versión interpretada por Jean Marais) o de la primera vamp del cine mudo -Irma Vep/Musidora (Los Vampiros, Louis Feuillade, 1915)- se encuentran también en la figura más andrógina de Vicente/Vera, con máscara, un body negro y esgrimiendo un cuchillo. 


\section{Carmen Peña Ardid}

-Matador (1986), Átame (1990), Kika (1993), entre otros títulos(Coelho/Gonzaga, 2013; Smith, 2011: 204-205).

No menos relevancia tienen en La piel que habito la pintura y la escultura, como formas artísticas que, imbricadas en la trama del filme, amplían la significación de los motivos tratados en la diégesis. Así, los cuadros de Tiziano, Jorge Galindo, Guillermo Pérez Villalta y Juan Gatti que presiden lugares estratégicos - pasillos, dormitorio, despacho- de la mansión del doctor Ledgard (Jung, 2014; Poyato Sánchez, 2015), asociándose a su voluntad de poder, pero también la hermosa cadena móvil, cambiante de color, de la estructura molecular del ADN que acompaña los créditos finales de la película. Y, sobre todo, la obra de la artista Louise Bourgeois, ligada al personaje de Vicente/Vera, para el que se convierte en tabla de salvación mental que inspira su creatividad superviviente $^{4}$. Esculpe con el propio cuerpo - al comienzo del filme- una postura de yoga que "cita" la escultura colgante Arco de histeria; ilustra la cuenta de los días de cautividad con imágenes de las Femme Maison y modela en plastilina pequeños bustos vendados con telas: figuras desestetizadas, des-generizadas, semejantes a las que confecciona Bourgeois, que además de metaforizar el dolor provocado por el bisturí del cirujano en este personaje, son la antítesis de la perfección estética que el doctor Ledgard-Pigmalión quiere imprimir al cuerpo transexuado de Vicente/Vera, la nueva criatura femenina que construye a su medida (Cabello Ruiz, 2014; Parés Pulido, 2014).

Este mapa transtextual ha sido objeto preferente de numerosos estudios ${ }^{5}$ y de las interpretaciones del filme que, desde el psicoanálisis, el feminismo y la teoría queer, han analizado el modo en que La piel que habito subvierte los patrones de género socialmente instituidos (Coelho/Gonzaga, 2013; Russo, 2019), plasma radicalmente los efectos traumáticos provocados por «la brutalidad de la violencia masculinista» (Martín, 2014: 110) o se adentra en una reflexión sobre la identidad que pone en entredicho la coherencia entre sexo biológico, género asignado y deseo sexual.

Se echa de menos, sin embargo, en estas múltiples lecturas de la película una atención mayor al vínculo existente entre La piel que habito y la novela Tarántula, de Thierry Jonquet, principal fuente de inspiración del

4 En los primeros momentos de su cautiverio, la imagen de un Vicente semidesnudo, de rodillas y hundiendo la cabeza en un balde de plástico azul, en busca de la última gota de agua, recrea la iconografía de la serie artística denominada Femme Maison que Bourgoise inició en la pintura ampliándola después a formas escultóricas.

${ }^{5}$ Añadamos la función narrativa de la canción de Ellen de Lima, Pelo amor de amar (Poyato Sánchez, 2015: 300) o, en el campo literario, las referencias explícitas a Escapada, de Alice Munro, e indirectas a El libro de los muertos. Apuntes 1942-1988, de Elias Canetti (Cabello Ruiz, 2014). Con un cuento de Balzac-Sarrasine-compara Barbara Zecchi varios motivos de la película (2015: 52). 
filme ${ }^{6}$. De ella toma, introduciendo importantes cambios, sin duda, el singular argumento, los rasgos de los principales personajes, la nociva relación entre captor y criatura, así como una estructura narrativa basada en anticipaciones, revelaciones sorprendentes y retrospectivas que introducen el punto de vista contrastado de varios personajes; unas estrategias que, además de crear suspense y jugar con la sorpresa, también contribuyen -especialmente en un filme que no quiere dejar de ser comercial- a mantener la complicidad de un mayor número de espectadores que quizá no estarían bien dispuestos a seguir una historia de venganza y sometimiento si desde el principio conocieran el origen de "Vera" y la naturaleza de su transformación".

En el momento del estreno de la película, el especial cuidado en no desvelar las incógnitas que encierra la trama favoreció las referencias superficiales a la novela por parte de la crítica. Pero el "olvido" posterior de esta obra, respecto a otros referentes artísticos, nos enfrenta al complejo problema de cómo nos acercamos a los géneros de la literatura popular y a las obras no canónicas, incluso cuando se reconoce su calidad, como es el caso de Tarántula ${ }^{8}$. Sin reclamar ninguna "relación de dependencia" de la película de Almodóvar respecto de la novela de Jonquet, creo que tiene interés acercarse a La piel que habito teniendo en cuenta la aportación de Tarántula, un relato en el que el papel convencional de la víctima atrapada corresponde a un varón-mujer ${ }^{9}$ y en el

\footnotetext{
${ }^{6}$ Una excepción al generalizado desinterés crítico es el trabajo de Ralf Junkerjürgen (2018) y, sobre todo, María Cláudia Rodrigues Albes y María Celeste Tomasello (2013)

${ }^{7}$ El descubrimiento de que la hermosa cautiva (Vera) era un guapo joven (Vicente) se produce cuando el espectador/a ya se ha identificado con y admirado a la frágil figura de apariencia femenina. Pese a ello, algún crítico mencionó los estallidos de risa de espectadores sorprendidos en el momento en que el Dr. Ledgard revela a Vicente que le ha hecho "una vaginoplastia". Esta ruptura deliberada del esquema dramático convencional busca, para Thomas Sotinel, «la modification du comportement des spectateurs» (2011). Evidentemente, esa «modificación» no llega a todos, como muestra la reseña crítica de Carlos Boyero (2011).

${ }^{8}$ Francisco A. Zurian - estudioso que presta alguna atención a la novela- se esfuerza en destacar sobre todo las diferencias: «The director has retained from the novel its main idea only to proceed to completely rework the plot, characters, setting, narrative temporality, and structure of events. Almodóvar invest his version with a clear narrative structure, composed of three distinct acts (including a surprising second act, studded with flasbacks) and a number of effective plots point» (2013: 262). No son menores, por ejemplo, los cambios que Luis Buñel imprime a la adaptación de la novela de Pérez Galdós, Tristana (1970), pese a lo cual nunca se desvincula del prestigioso precedente literario (Peña Ardid, 2004).

${ }^{9}$ Refiriéndose a la tradición literaria, observa Margaret Atwood que, frente a la figura femenina de la "plañidera solitaria" que sufre todo tipo de percances y cuya única actividad es huir, «para los hombres adultos mostrar esas características -temor, incapacidad de actuar, sentimientos de indefensión absoluta, llanto, sensación de estar atrapado y desamparado- supone o estar loco o ser miembro de
} 


\section{Carmen Peña Ardid}

que la metamorfosis del cambio de sexo no se disfraza de duplicidades morales más o menos sexistas - pienso en el filme Dr. Jekyll and Sister Hyde (Roy Ward Baker, 1971)-, sino que constituye el núcleo de una venganza restitutiva que obliga a quien la padece a enfrentar un nuevo destino. Por otro lado, las diferencias de La piel que habito con la novela de Thierry Jonquet, además de impulsar el diálogo con otros referentes artísticos como los anteriormente mencionados, remiten al peculiar universo temático, simbólico e iconográfico del cineasta manchego e invitan a valorar también el alcance de los cambios que se han producido en el tratamiento de la transexualidad entre 1984, el año de publicación de la novela, y 2011, el de la producción del filme.

\section{TARÁNTULA: UNA GALATEA TRANSEXUAL}

Tarántula ${ }^{10}$ narra a dos voces, de forma fragmentaria y con un marcado desorden temporal la desasosegante historia de una venganza arquetípica e insólita a la vez: la venganza de un padre -el prestigioso cirujano plástico Richard Lafargue- contra el joven Vincent Moreau, al que considera único autor de la brutal violación de su hija Viviane. Lo secuestra, lo somete a una operación de cambio de sexo y, convertido en la bella Ėve, lo obliga a prostituirse, transformándose él mismo en un voyeur-testigo de sus sufrimientos, único medio de calmar el dolor que siente por el estado de enajenación en el que se encuentra su hija. Vincent lleva cuatro años desparecido al comenzar la novela y sabremos que lo sigue buscando su madre y que lo recuerda sobre todo su amigo de correrías juveniles, Alex Barny, coautor de la violación de Viviane, que está huyendo de la justicia tras asaltar un banco y matar a un policía. Por azar, Alex ve un documental de televisión en el que el profesor Lafargue habla de la cirugía plástica facial y secuestra a la que cree su esposa para obligarle a que le opere el rostro. Su violenta intervención extrema el calvario físico y psíquico de Vincent/Ève, aunque afecta también al doctor Lafargue, que engaña fácilmente a Alex, lo apresa y corre a liberar a su criatura. En el momento en que Ève reconoce al antiguo amigo -que no puede identificarla-, se desvelan los últimos enigmas de la trama y, con su muerte, se transforman las destructivas relaciones de odio que mantenían Richard y Ève.

Dividida en tres partes («La araña»; «El veneno»; «La presa»), la novela se inicia in medias res con la presentación, por un aséptico narrador

una minoría. Este tipo de sentimientos suelen considerarse una degradación de la naturaleza masculina, mientras que los mismos sentimientos en un personaje femenino se consideran la expresión de su personalidad. En los hombres la pasividad frente al desamparo es una aberración; las mujeres pasivas están dentro de la norma” (2006: 33)

${ }^{10}$ Para una introducción a la figura y la obra del escritor francés Thierry Jonquet, «maestro de la novela negra dentro del movimiento denominado en Francia "neopolar", impulsado en los años setenta por Jean-Patrick Manchette», véase Herrero Cecilia (2011). 
omnisciente, de la figura del doctor Richard Lafargue: un hombre culto, viudo - perdió a su mujer en un accidente de avión-que dirige en París un Servicio de Cirugía Plástica de fama internacional, posee una clínica privada en Boulogne y una lujosa villa en las afueras, donde, pese a su imagen externa de gran respetabilidad, tiene prisionera a la joven y hermosa Ėve, con la que mantiene una ambigua relación de esmeradas atenciones e insólita crueldad. Hay en el personaje un lado oscuro y destructivo - revelador de «la duplicidad y escisión de su personalidad» (Camero, 2011: 239)- ${ }^{11}$ que se intensifica cada vez que visita a su hija Viviane en el psiquiátrico o cuando la joven sufre una crisis de automutilación, lo que lleva a Lafargue, ciego de odio, a obligar a Ève a prostituirse en un estudio alquilado en el centro de París, mientras él contempla, tras un falso espejo, el trato vejatorio que le dispensan los clientes más violentos. Alternando con este relato, el narrador sigue la peripecia del delincuente Alex Barny, manteniéndose más próximo a sus pensamientos, que perfilan una condición brutal y primaria en contraste con la más inteligente y sensible de su amigo Vincent ${ }^{12}$.

Muy distinta es la otra voz que narra los hechos en Tarántula desde la subjetividad desdoblada del discurso en segunda persona (representado en cursiva). Es el diálogo interior de quien dice llamarse «Vincent Moreau» y habla consigo mismo para sobrevivir a la desventura de su sometimiento, aunque el empleo del «tú» ya desdobla al sujeto desde que comienza su ejercicio de memoria («Recuerda. Era una noche de verano... Conducías deprisa...», Jonquet, 2007: 21) y, poco a poco, pasa a ser el no-yo que sufre la tensión de una identidad psíquica y corporal escindidas. La voz de Vincent/Ève evoca su captura, los meses de encierro marcados por la sed, el silencio, la ignorancia de las causas de su pesadilla. Cuenta cómo el hombre sádico y misterioso que lo retiene, al que llama «Tarántula» y «amo», le quita las cadenas, le permite cierta higiene y, con el tiempo, le ofrece manjares, libros, buena música, pinturas, incluso un piano. Comienza también el tratamiento de pastillas, inyecciones y el hábito de fumar opio para calmar su ansiedad. Es el «veneno» que le inocula Tarántula («una araña con múltiples redes», Jonquet, 2007: 101), provocándole la pérdida del deseo sexual e inquietantes transformaciones

${ }^{11}$ El personaje de Jonquet también es heredero del Dr. Génessier, el brillante cirujano de Los ojos sin rostro, que rapta chicas jóvenes para utilizar su piel en la reconstrucción del rostro de su hija.

${ }^{12}$ La tosquedad de Alex Barny - contrafigura de Vincent Moreau- se desplaza en la película al personaje de Zeca - el medio hermano brasileño de Robert Ledgard, que seduce a su esposa Gal y provoca el accidente que le desfigura el rostro. Con grotesco disfraz de tigre, llega a la mansión del doctor también con la intención de que le opere el rostro. Ambos buscan mediante el chantaje un cambio de apariencia y mueren engañados por las apariencias. Alex se engaña al no reconocer en Ėve a su amigo Vincent; Zeca se engaña al reconocer a Gal, su antigua amante rediviva, en el cuerpo transexuado de Vicente/Vera. 


\section{Carmen Peña Ardid}

como el crecimiento del pecho. Antes de contar la verdad del sometimiento de Vincent a un cambio quirúrgico de sexo, hay claros indicios de que él y Ève -actores/actantes distintos en la trama- son un solo personaje, y de que Richard Lafargue es Tarántula ${ }^{13}$. También es un acierto que el discurso interior de Vincent alterne de pronto el empleo del género gramatical masculino y el femenino, según hable de su vida pasada o se acerque al presente de su nueva identidad ${ }^{14}$. Cuando, al final, Ève se convierte, sin saberlo, en «la presa» de Alex y Tarántula le muestra su cara más compasiva y protectora, el relato retrospectivo de Vincent evoca, como si fuera un sueño, el momento más cruel de Tarántula, cuando le practicó la reasignación de sexo; una operación que, en la novela de Jonquet, a diferencia de la película de Almodóvar, se describe con gran precisión científica, empleando el recurso de reproducir la voz en off del documental médico que el doctor proyecta en una pantalla para que lo vea la nueva criatura, regocijándose con su estupefacción y su horror ${ }^{15}$.

Tarántula no es una novela de anticipación científica, aunque la impronta mítica que posee explica «un exceso de perfección, un encanto demasiado deslumbrante» (Jonquet, 2007: 54) en los logros del cirujano plástico al transformar a Vincent en Ève. Por otra parte, como ha observado Carmen Camero, Tarántula aparece en una época «en la que la cuestión del transexualismo ha traspasado ya el exclusivo ámbito especializado de la ciencia y la medicina para convertirse en palabra de todos. Revistas, periódicos, literatura, emisiones televisivas... hablan de esta controvertida y difícil cuestión trans» (2011: 235-236). Pese a ello, el

${ }^{13}$ «Pero con el tiempo, poco a poco y sin darte cuenta, acabaste jugando a otro juego. Un juego cuyas reglas había establecido Tarántula: el juego de la oca de tu degradación... Una casilla/sufrimiento, una casilla/regalo, una casilla/inyecciones, una casilla/piano... Una casilla/Vincent, una casilla/Ève» (pág. 102). Sobre la simbología andrógina de los cisnes del jardín de Lafargue, véase Mucha (2016: 128). ${ }^{14}$ «En cuanto entraba en tu habitación, si estabas sentada al piano, te ponías a tocar The Man I Love, esa canción que detesta [...] ¿Cuánto tiempo te va a dejar pudriéndote en este sótano? La primera vez, tras la persecución por el bosque, te dejó ocho días solo en completa oscuridad» (pág. 100). La cursiva es mía.

15 «"Tras haber administrado un tratamiento hormonal durante dos años, procederemos a practicar una vaginoplastia al señor X [...]. Después de la anestesia, empezaremos cortando un colgajo de glande de 1,2 centímetros, luego desprenderemos la totalidad de la piel del pene hasta su base. Diseccionaremos el pedículo, también hasta el nacimiento... [...]. La siguiente fase consiste en practicar una incisión escrotoperineal cuyo extremo posterior debe quedar a 3 centímetros del ano [...]”. Tarántula reía, reía... De vez en cuando se levantaba para enfocar la imagen, volvía a tu lado y te daba unas palmadas en la mejilla. "La tercera fase consiste en la creación de una neovagina entre el plano uretral por delante y el recto por detrás $[\ldots]$. Aquí podemos observar al mismo paciente varios meses más tarde. El resultado es muy satisfactorio: la vagina es de un tamaño adecuado y absolutamente funcional, el clítoris está dotado de sensibilidad [...]”» (págs. 122123). 
planteamiento naturalista y a la vez perturbador de la novela lleva a preguntarse «si el discurso científico y racional ha sido capaz de vencer nuestras creencias y miedos más ancestrales», si el transexualismo se ha convertido en algo tan «familiar» desvinculado de la inquietud que provoca el desarrollo científico y, en no menor medida, las teorías y prácticas que desestabilizan algunas nociones sobre la identidad humana al poner en cuestión la estabilidad binaria de los sexos y géneros normativos. Un cambio de sexo involuntario es sin duda una experiencia terrorífica, aunque, significativamente -volveré sobre ello- ni en Tarántula ni en $\mathrm{La}$ piel que habito se genera un ser imperfecto o monstruoso - en la estirpe de Frankenstein-, quizá porque tiene la forma de una mujer.

Cuando Richard Lafargue bautiza a Vincent con el nombre de Ève sanciona, como el legislador, la coherencia entre el sexo y el género propia del ideal científico heteronormativo que rige las operaciones de transexualidad (Preciado, 2011: 120) ${ }^{16}$. Y no evoca en vano a la primera mujer del Paraíso bíblico, ya que actúa como Yahvé cuando creó a Eva a su imagen, pero como un ser secundario, derivado del varón (aunque aquí no emplee una costilla). A la vez, la historia de Lafargue reelabora el mito misógino de Pigmalión desde que su hija Vivanne, como consecuencia de la violación, se transforma en algo inerte sin sentimiento ni emoción (Jonquet, 2007: 18). Castiga al violador convirtiéndolo en una mujer a la que cosifica y enseña a vender su cuerpo y su belleza (evocando a las disolutas Propétides del mito, transformadas en rocas) hasta que, asqueado de tanta violencia y viéndola maltratada por otros, la percibe viva en el sufrimiento y su odio se disipa al caer en la cuenta de que él la ha creado y educado, según su deseo y a imagen de su ideal («El sufrimiento de Ève, que le pertenecía porque él había modelado su destino y su vida, lo llenó de repugnancia y de compasión», 2007: 72). Como señala de nuevo Carmen Camero, en los cuatro años de encierro, Vincent, «el joven violador, chico de pueblo que, en compañía de su amigo Alex, recorre bares y fiestas de localidades cercanas en busca de aventuras sexuales» se ha metamorfoseado en Ève, «un ser culto y refinado que lee a Balzac y a Stendhal, juega al ajedrez, oye música, toca el piano y pinta» y podrá llegar a ser un miembro más de la clase alta $(2011: 244)^{17}$. Esta modelización del

\footnotetext{
16 «-Querido Vincent, vamos a celebrar el primer aniversario de alguien a quien acabarás conociendo bien: Ève. Señaló tu pubis. Ahí ya no hay nada. Verás, voy a explicártelo: ya no eres Vincent; te has convertido en Ève» (Jonquet, 2007: 122). En la película, la asignación de un nuevo nombre se produce cuando la figura "está acabada”: «las manos del DOCTOR LEDGARD le quitan la máscara aséptica del rostro. Debajo se revela un bello rostro de mujer, con el pelo corto, le ha crecido como un centímetro. VICENTE: abre los ojos. DOCTOR LEDGARD: No puedo seguir llamándote Vicente. A partir de ahora te llamarás Vera. El hombre bautiza su obra con un nombre que transmite autenticidad» (Almodóvar, 2011: 118).

17 «Las inyecciones carecían de importancia. Tarántula era tan amable... Hacías rápidos progresos en música. Tarántula, impaciente, pasaba horas buscando
} 


\section{Carmen Peña Ardid}

espíritu - no tan acentuada en la película- será un factor importante en la elección de su destino, ya que la subyugación de Vincent en la novela implica la desaparición del ser que era anteriormente. Las palabras que le ayudan a sobrevivir dan a la vez testimonio de la despersonalización que ha sufrido, sintiéndose un animal atrapado, luego un esclavo, una cosa, un fantasma (sufriente) ${ }^{18}$, notando cómo se difuminan los recuerdos del mundo al que perteneció. El cambio de sexo, para Vincent, no es solo un trauma físico y psíquico íntimo sino la pérdida de su potencia viril y de una existencia social reconocible por los suyos:

Tarántula te visitaba todos los días y pasaba horas contigo. Hablabais de tu nueva vida, del ser en el que te había convertido...

Volviste a tocar el piano, a pintar... Puesto que tenías pechos y ese orificio entre las piernas, no te quedaba más remedio que entrar en el juego ¿Escapar? ¿Volver a tu casa después de tanto tiempo? ¿Tu casa? ¿El lugar donde Vincent había vivido era realmente tu hogar? ¿Qué dirían las personas que él había conocido? No tenías elección. Maquillaje, vestidos, perfumes. Y un día Tarántula te llevó al bosque de Boulogne. Ya nada podía afectarte (Jonquet, 2007: 124-125).

Veremos precisamente que la respuesta a estas preguntas y al dilema identitario que entrañan es uno de los aspectos que más aleja La piel que habito de Tarántula. En la novela de Jonquet, Richard Lafargue cierra la herida del odio por la violación de su hija Viviane al descubrir que había un responsable más, Alex, al que da muerte tras haber salvado esta vez de sus garras a su nueva y amada criatura (Ève). Ya no quiere imponerse a ella y, para demostrárselo, pone su vida en manos de la joven, que renuncia a matar a su creador y acaba convertida en su aliada ${ }^{19}$. En Tarántula, según Márcia Mucha, la violencia conduce a la redención -tanto del que la ejerce como del que la padece-, como lo grotesco transita a la esfera de lo sublime (2016: 135). Para Carmen Camero, por encima de la intriga, es la misteriosa identidad del ser humano y su capacidad de transformación el tema de una novela que, mediante la actualidad del transexualismo y la

partituras en las tiendas especializadas. En cuanto al dibujo, en el sótano se apilaban los manuales y los libros de arte que te servían de modelo» (Jonquet, 2007: 77).

18 «Él ha aniquilado hasta el menor atisbo de rebeldía que hubiera en ti. ¡Te has convertido en su objeto! ¡Te has convertido en su objeto! ¡Ya no eres nada!» (Jonquet, 2007: 98); «¿Morir? Pero si llevas ya dos años muerto. Vincent murió hace dos años. El fantasma que le sobrevivió nunca ha contado para nada» (págs. 100-101).

${ }^{19}$ Lo expreso en estos términos porque, después de la muerte de Alex, Ève toma la mano de Richard, apoya la cabeza en su hombro y le susurra: «Ven..., no podemos dejar el cadáver aquí» (Jonquet, 2007: 138). Ayudándole a deshacerse del cadáver del que fuera su amigo, Ève entierra también su pasado y parece dispuesta a vivir junto al que fue su captor y aceptando su nueva identidad en una relación más igualitaria. ¿Ha triunfado Pigmalión? 
intervención de la ciencia médica, revive mitos clásicos en torno a la metamorfosis. Uno de los principales cambios que introduce La piel que habito es el desenlace de esta historia de violencia, torturas y mentes desequilibradas tan cercana a la novela gótica y que «desemboca en el descubrimiento de la comprensión y la ternura» (Herrero Cecilia, 2011: 352). Almodóvar propone otro final esperanzador (Zurian, 2013: 276), sin duda más político, que somete a juicio sumarísimo el abuso del poder y apuesta por la capacidad de emancipación del sujeto sometido. Por otro lado, en Tarántula -escrita en 1984-, el cambio (forzado) de sexo biológico ya saca a la luz la construcción cultural del género, que impone a Vincent el aprendizaje de una determinada feminidad. Pero no cuestiona la correspondencia causal del sexo al género ni el binarismo heteronormativo que mata a Vincent para que nazca Ève. En 2011, La piel que habito, en sintonía con nuevos planteamientos del feminismo y con la teoría queer, reformula la comprensión de estos parámetros (este modelo de metamorfosis) al plasmar con el personaje de Vicente/Vera una visión antiesencialista y relativamente autónoma de las categorías de sexo biológico, expresión de género y orientación sexual; esto es, la separación entre identidad de género y verdad del cuerpo, sugerida ya en el título de la película.

\section{LA PIEL QUE HABITO}

Es indudable que, en este filme, no ha pretendido Almodóvar ofrecer una "simple" interpretación -ni siquiera autorial- de Tarántula, sino una obra distinta, erigida sobre su base, que introduce temas nuevos y da cabida, como hemos apuntado, a otros referentes artísticos muy valiosos para su sentido ${ }^{20}$. El hecho de que no conserve el título de la obra de Jonquet (aunque se reconozca la filiación en los créditos finales) es un modo de subrayar su autonomía, creando además una distancia muy interesante con el texto literario, al desplazar el centro de atención desde la figura del doctor-carcelero-Pigmalión (Tarántula) a la de su cobaya metamorfoseada, a ese "yo" que en la frase "La piel que habito" habla de una parte de su cuerpo como si fuera un envoltorio extraño a su ser más íntimo con el que no se identifica. El cine de Almodóvar, como bien se ha señalado, ha convertido el cuerpo, con toda su polisemia, en un tema

\footnotetext{
${ }^{20}$ No obstante, aunque no puedo hacer un análisis pormenorizado, es destacable el hábil aprovechamiento y transformación de un buen número de motivos "menores" procedentes de la novela (las canciones «The Man I Love» y «Pelo amor de amar» asociadas al trauma de la violencia y la pérdida; la contemplación voyeurista de los doctores; la duplicidad de los personajes masculinos: Vincent-Alex/Robert-Zeca; la obsesión de sustituir a las mujeres amadas perdidas: Ève en el lugar de la hija Vivianne; Vera en el lugar de la esposa Gal; el goce que encuentra Vincent/Ève en las artes, $\mathrm{y}$, concretamente, pintando un grotesco retrato de Richard/Tarántula travestido, actividad que tendrá su propia plasmación, mucho más original, en los dibujos y pequeñas esculturas que confecciona Vera).
} 


\section{Carmen Peña Ardid}

constante de reflexión (Seguin, 2009). Y ello se acentúa en el caso de esta película, vinculada al género cinematográfico del body horror (Gascón-Vera, 2014: 58), no solo porque sitúe en el centro de la trama la transexualidad y la transgénesis, sino porque, de principio a fin, la atraviesan cuerpos violados (Norma, Vera), sometidos a encierro y tortura (Vicente), cuerpos lacerados (el rostro quemado de la esposa del doctor), amputados, disciplinados (la práctica del yoga), objetos de representación (maniquíes, figuras de Louise Bourgeois) o de vigilancia, sin olvidar las máscaras y «las referencias constantes al recubrimiento del cuerpo» (Sánchez Noriega, 2017: 143). "La piel" extrañada del título encierra el secreto de varias metamorfosis corporales: la perfecta piel transgénica que cubre el cuerpo de Vicente/Vera, las formas femeninas y la imposición de un rostro ajeno que además reproduce los rasgos de otro ser (la esposa muerta del doctor), y la verdad anatómica y biológica de un cambio de sexo irreversible. El relato de estas desventuras no es asumido sin embargo por el "yo" que habla desde esa piel. El filme adopta la omnisciencia espectatorial, aunque incorporando parte del discurso interior de Vincent en la novela a través de dos flashbacks subjetivos - en los que se descubre el lazo que liga a Vera con Vicente- y del simbólico diario mural que este personaje pinta durante su encierro. El dilema de su identidad -quién era, en qué se ha convertido, cómo nombrarlo- mantendrá hasta el final las expectativas del filme que se abre y cierra con su figura, desde que vislumbramos a Vera tras una ventana enrejada practicando yoga, enfundada en un body del color de la piel y contorsionándose como la escultura Arch of Hysteria de Louise Bourgeois, hasta que escapa luciendo un ajustado vestido de flores para reencontrar a su madre y su amiga Cristina y atreverse a declarar: «Soy Vicente».

\subsection{El cirujano-artista y la mujer hecha a su medida}

La piel que habito sitúa el presente de la historia en un tiempo «modestamente futurista: "Toledo, 2012"» (Smith, 2011: 203), cuando el cirujano plástico Robert Ledgard (Antonio Banderas) ha materializado también su venganza contra el joven Vicente (Jan Cornet), el autor de la violación de su hija Norma (Blanca Suárez), al que ha cambiado de sexo, y está a punto de dar su "obra” por terminada («iTe gusta lo que ves? ¿Hay algo más que quieras mejorar de mí?», le preguntará Vera). La primera parte del filme gira en torno a la figura de Ledgard, a los secretos que envuelven su existencia y los logros de su investigación científica. La secuencia de apertura ya muestra dos de sus posesiones: la gran mansión "El Cigarral", rodeada de olivos en un enclave aislado a las afueras de Toledo, y, cautiva en ella, la joven Vera (Elena Anaya), a la que custodia el ama de llaves Marilia (Marisa Paredes), y vigila, sobre todo, un inquietante ojo-cámara incrustado en la pared de su habitación (que vemos, al comienzo, proyectando una sombra alargada con la forma de un falo). Las secuencias posteriores presentan al doctor Ledgard disertando en un aula 
sobre su intervención en avanzadas operaciones de reconstrucción del rostro, investigando en el laboratorio privado de su mansión o dedicado a la habilidosa tarea de colocar fragmentos de tejido epitelial sobre un maniquí de plástico, que se transmuta luego en Vera, hasta que culmina con éxito el trasplante en su cuerpo de una piel artificial que prueba ser sensible, pero ignífuga e inmune a la picadura de cualquier insecto. Ledgard ha investigado durante años el cultivo de esa nueva piel que obtiene mediante la transgénesis (transfiriendo información genética de una célula de cerdo a una célula de piel humana para endurecerla) y a la que llama GAL en memoria de su esposa, que se suicidó arrojándose por una ventana al no poder soportar la visión de su rostro quemado tras un accidente de coche. Cuando expone ante sus colegas los resultados de su trabajo, el presidente del Instituto de Biotecnología le amonesta por su hybris, recordando el terminante rechazo de la bioética al empleo de la terapia transgénica en humanos, sin saber que Ledgard ha traspasado límites más graves de la ética, que lo sitúan en la estela del doctor Génessier, el cirujano sin escrúpulos de Les yeux sans visage que secuestra jóvenes para extraer la piel de su rostro y trasplantarlo al rostro dañado de su hija ${ }^{21}$. Ledgard converge con él y con tantos otros mad doctors al emplear el saber científico no bajo el orden de la razón -y el amparo de las instituciones-, sino el de las pasiones individuales. Califica su trabajo sobre la piel como «una aventura personal» que remite -así lo averiguaremos en la segunda parte del filme- a la novela familiar del doctor (Molina Foix, 2012:10), hecha de traiciones, pérdidas violentas - la esposa y la hija-, sentimientos de venganza y amores necrófilos; hecha también de la «locura» atávica que dice llevar Marilia en sus entrañas, la madre de dos hijos sociópatas (Robert y Zeca). Toda esta vertiente trágica tiene mucho más recorrido en el filme que en Tarántula, al igual que la melancolía inherente a algunos motivos románticos (Molina Foix, 2012: 10; Sánchez Noriega, 2017: 375) o las reminiscencias góticas de un filme que no olvida la tradición del cine de terror ${ }^{22}$.

La mansión de "El Cigarral" no solo alberga una sala de cirugía y un sofisticado laboratorio; es también un museo de obras de arte, signo de la riqueza de Ledgard y de sus pasiones megalómanas (como denotan las grandes reproducciones de cuadros de Tiziano). Más allá de la cita

\footnotetext{
${ }^{21}$ Como apunta Poyato Sánchez, otras notables concomitancias con este filme son «la vertebración de los espacios interiores de la casa-clínica [...], la fuerte presencia visual de las escaleras y, sobre todo, la inscripción en las imágenes de un rostro femenino que, desposeído de la piel, se enfrenta a su imagen en el espejo» (2015: 291).

${ }^{22}$ Así, la iluminación del rostro de Ledgard -custodiado por dos cabezas de maniquí- durante su primera conferencia; o la aparición de una intensa luz roja en el techo del sótano de "La Maternidad" cuando recoge unas muestras biológicas. La apariencia de una catedral del saber tiene el escenario de la biblioteca donde el doctor se dirige a sus colegas como un demiurgo desde un púlpito elevado.
} 


\section{Carmen Peña Ardid}

artística, La piel que habito se esmera en vincular ciencia y arte - no en vano convergen los mitos de Frankenstein y Pigmalion-, la creatividad científica y la artística, consideradas además en su relación con el poder (y con la falta del mismo). Vera emerge en el filme como un objeto escultórico, una muñeca y, a la vez, un cuerpo con costuras-cicatrices. Es la cobaya enjaulada que usa la pared como lienzo y que, inspirándose en la artista Louise Bourgeois, de quien toma el lema «El arte es garantía de salud», da forma expresiva al trauma del encierro y al despojamiento de su identidad sexual reproduciendo figuras de las Femme Maison o pequeños bustos sin rostro definido que cubre con pedazos de los vestidos femeninos que se niega a usar ${ }^{23}$. Ha sido bien observado, por otra parte, que «las escenas de corte, incisión, pegado y cosido igualan la tarea médica de Robert y la artística de Vera con las labores de montaje de un filme» (Molina Foix, 2012: 9; Thibaudeau, 2012: 198). Y en la asociación del cirujano con un director de cine abunda Barbara Zecchi, para quien «los focos del quirófano parecen los de un plató, o el aparato con el cual modifica los contenidos de unas ampollas parece un rollo de película» $(2015: 47)^{24}$. De hecho, la estilización que caracteriza al cine de Almodóvar está muy acentuada en las imágenes que describen aquí tanto el proceso de la transgénesis como el del trasplante de la piel - «cuando el filme se aparta de la matriz narrativa para realizar una suerte de documental científico» (Poyato Sánchez, 2015: 288)-. Retenemos, en un caso, la bella composición abstracta de las células de la sangre en los recipientes de cristal de la moderna tecnología médica; en el otro, la imagen del cirujano plástico como un artista-escultor-costurero que dibuja, rehace y cubre la superficie de un cuerpo cuya metamorfosis física se produce mediante la elipsis, la sobreimpresión y el fundido o, sobre todo, la máscara que oculta el trayecto doloroso hasta que emerge la nueva criatura a la que Ledgard

\footnotetext{
${ }^{23}$ Ya he mencionado la importancia que, en Tarántula, tiene para Vincent la música, la lectura de los clásicos y la pintura («Dibujaste, torpemente al principio, luego cada vez mejor hasta acabar recuperando tu antigua habilidad. Bosquejabas retratos sin rostro, bocas, paisajes caóticos, el mar... Pegabas los dibujos en la pared... para olvidar el cemento desnudo», Jonquet, 2005: 58). Almodóvar centra estas aficiones en la lectura y, sobre todo, en la expresión plástica (que prolonga la labor de Vicente cuando viste maniquís en la tienda de ropa de su madre), pero incorporando la referencia a una propuesta artística muy potente y singular -la que representa la obra (y la vida) de Louise Bourgeois- que salva al personaje y es clave en el discurso del filme sobre la identidad sexo/género. Para un análisis de ese vínculo, véase Cabello (2014: 41-43), Martín (2013: 121-124) y Pares Pulido (2014).

${ }^{24}$ Recordemos que, para Eisenstein, literatura y cine estaban emparentados por la línea del instrumento de trabajo dominante: las tijeras. «iAh, las tijeras!, ¡Quién podrá cantar dignamente al favor que vosotras prestáis [...]. Yo quisiera ser representado con unas tijeras, como una costurera... Así, en el filme como en el libro, las tijeras del montador son el último regente de la fisonomía y el alma» (1982: 17).
} 
ha dado, además de una piel excepcional, el rostro de la esposa perdida, Gal (abreviación de Galatea) y el nuevo nombre de Vera.

«El doctor Frankenstein -observa Pedro Almodóvar- no podía enamorarse del monstruo que creó, pero el doctor Ledgard sí. Y aquí el mito de Galatea, del escultor enamorado de su obra, desplaza a los otros mitos» (2012: 163). Ledgard no solo es un científico, sino un esteta. Cuando no trabaja "con” su criatura en el quirófano, la observa en la gran pantalla de su dormitorio que emite imágenes grabadas - solo para él- por el ojo-cámara mostrado al inicio. Bajo la mirada contemplativa de Ledgard, inicialmente casta como la de Pigmalión, Vera se convierte en espectáculo y cobra otro valor sublimada como obra de $\operatorname{arte}^{25}$. De ahí el placer voyeurista que siente Robert mirándola a distancia, "enmarcada" y en poses que emulan las representaciones del desnudo mitológico femenino de Pérez Villalta y Tiziano $^{26}$ que adornan las paredes de su mansión. Almodóvar enfatiza el efecto cuadro, teatralizador, en los paralelismos que crea - en el atrezzo y posturas de sus personajes- con las escenas de estos modelos de la tradición pictórica - patriarcal-, que se amplían a la Venus del espejo de Velázquez, o "Las Majas" de Goya. Fascinado por Vera como imagen, refuerza su "feminización" en un plano simbólico y puede nacer en él esa clase de amor llamada eidolismo (Pedraza, 1998: 34). Por el contrario, la cercanía todavía lo perturba, pues pone en peligro un control que dista de ser absoluto. Así se insinúa cuando agiganta con el zoom el rostro de Vera, que le devuelve la mirada, o cuando rompe el hechizo pictórico, entra en su cuarto para ofrecerle una pipa de opio (como Dioniso ofrece vino a Ariadna) y descubre la sangre de quien, al agredirse, muestra su resistencia a ser la $\left\langle\right.$ criatura a su medida» ${ }^{27}$.

El voyeurismo escópico de Ledgard no subyuga a Vera en términos tan sádicos como los empleados por Lafargue en Tarántula cuando obliga a Ėve a someterse a otros hombres y disfruta siendo testigo de las vejaciones que sufre. En La piel que habito desaparece el castigo de la prostitución para

\footnotetext{
${ }^{25}$ Es la mirada de Ledgard la que transfigura la realidad, como se advierte la primera vez que le vemos encender la pantalla que muestra la habitación de Vera. Aparece la imagen naturalista de una mujer desnuda, recostada de espaldas en la cama, y de ahí pasamos al primerísimo plano de la cámara subjetiva que recorre la superficie de su piel, dotada ahora de otro colorido, de una luz pictórica focalizada en el glúteo de la figura, evocando la figura mitológica de Ariadna representada en el cuadro de Pérez Villalta (Dionisos encuentra a Ariadna en Naxos, 2008) que acabamos de ver en el dormitorio del doctor.

${ }^{26}$ Presiden los pasillos de la mansión reproducciones de la Venus de Urbino (1538) y Venus recreándose con el amor y la música (1555).

${ }^{27}$ Los cortes superficiales que se ha hecho Vera, ¿no hacen pensar en la agresión con una cuchilla que, en marzo de 1914, realizó la militante sufragista Mary Richardson contra la Venus del espejo de Velázquez en The National Gallery de Londres? Véase el análisis que hace Lynda Nead de cómo relató la prensa el daño a la pintura como si se hubiera magullado la blanda piel de una bellísima mujer (1998: 67-69).
} 


\section{Carmen Peña Ardid}

introducir el tema de la piel transgénica y el cambio de rostro. Pero lo que me interesa señalar, más allá de estas diferencias, es el hecho de que, en ambos casos, la reasignación de sexo de varón a mujer no es el objetivo último de la venganza, sino la condición previa - el desempoderamiento viril y el borrado del cuerpo masculino- para poder subyugar al nuevo ser femenino que «respira por la vagina», sometido a vejaciones físicas, la experimentación científica o incluso al amor. Este cambio forzado de sexo no solo es traumático en cuanto que no elegido; puede considerarse un rebajamiento en la escala de lo humano.

\subsection{El tiempo de las revelaciones}

El sueño de poder de Robert Ledgard se ve amenazado por malos augurios antes de que su hermanastro Zeca (Roberto Álamo), apodado el Tigre, irrumpa en "El Cigarral”. Como una voz del coro trágico, Marilia le advierte del grave error que ha cometido al dotar a Vera de rasgos tan semejantes a los de Gal; habla de matarla, pues intuye que el amor que se está despertando en él lo «devore como un cáncer». También Vera/Gal, una criatura nada dócil, interpela a su creador sobre el destino que le aguarda, retándolo a la posibilidad de «convivir», momento en que Ledgard despide a los criados de la casa y deja, sin saberlo, paso franco al "intruso" Zeca, que con un ridículo disfraz de tigre amenaza por segunda vez sus bienes más preciados. Narrativamente, la función de este personaje es similar a la de Alex Barny en Tarántula, cuya violencia desvela enigmas de la trama y provoca un cambio en la relación de los protagonistas. Pero Zeca, hijo de Marilia y hermanastro de Robert, reaviva una historia familiar oculta y trae consigo un retorno de lo reprimido: el "pecado" de Marilia al no poder velar por igual por sus dos hijos de distintos padres, la ignorancia de Robert de la identidad de su verdadera madre y del vínculo que le une a un delincuente como Zeca, quien, once años atrás, huyó con su esposa y dejó que ésta se abrasara tras tener un accidente de coche. Ahora Zeca muestra una marca de nacimiento para que Marilia lo reconozca bajo el disfraz con el que se oculta de la policía y, ya en la casa, cree reconocer a $\mathrm{Gal}^{28}$ en la mujer que aparece en las pantallas de vigilancia incitándole a saciar un apetito sexual incontrolado. Somete a su madre - como hiciera Paul Bazo con la hermana en Kika- para poder rastrear la "presa", atraparla y comérsela sexualmente. Su mirada es pura gula cuando lame la pantalla y borra toda distancia entre la imagen y la mujer-cervatillo, a la que inmoviliza bajo uno de los cuadros de Tiziano, como si fuera una figura del Bosco profanando la idealidad platónica del desnudo de la diosa Venus. Este hombre-alimaña, extravagante y carnavalesco, es la contrafigura del doctor Ledgard, aunque no en un plano ético, sino en el

${ }^{28}$ El recurso de la anagnórisis, que revela identidades ocultas, es empleado en el filme para introducir giros en la acción y favorecer al final la reintegración de Vicente/Vera a su núcleo familiar-afectivo originario. 
refinamiento -también para el mal- que proporciona el dinero, el poder social, la educación y la cultura. Ledgard sorprende a Zeca yaciendo sobre su víctima como si la traición de la esposa «se repitiese». Duda de a quién dar muerte (mientras Marilia murmura: «¡Mátala! ¡Mátalos!»), pero le conmueve la intensa mirada de Vera y mata a Zeca, conservándola a ella consigo $^{29}$.

El avance del relato se detiene en la parte central del filme para abrirse al pasado que contiene la clave de los enigmas creados en torno a los personajes. Mientras Robert entierra el cadáver de Zeca, Marilia quema las sábanas manchadas con la sangre de su hijo y cuenta a Vera una historia familiar que ni siquiera Ledgard conoce del todo. La del nacimiento de sus dos hijos en Brasil, la disparidad de su crianza y su "locura" («de niños sólo jugaban a matarse»). Ante las llamas de la hoguera, el relato oral hace surgir las visiones de la omnisciencia: el coche incendiado en el accidente, los cuidados que dispensa Robert a su esposa carbonizada o el momento en que Gal se levanta de la cama atraída por el canto de su hija en el jardín y, al ver su rostro reflejado en el cristal, se arroja por la ventana cayendo a los pies de la niña que, desde entonces, queda traumatizada y sigue su mismo camino años después.

Tras este primer acto trágico, las revelaciones posteriores ya no se presentan como relatos de la consciencia sino que brotan de lo más profundo de la psique de Robert y Vera, justo cuando parece posible que nazca entre ellos un vínculo amoroso. La noche en que duermen castamente abrazados la narración retrocede seis años hasta el día de la violación de Norma en que ligaron sus destinos. El primer flashback se focaliza en el sueño de Ledgard, al que atormenta el recuerdo obsesivo, teñido de culpa, del día en que asistió con su hija Norma a la boda de doña Casilda $^{30}$ y hubo de encontrarla desmayada en el jardín y rechazando histéricamente sus caricias al identificarlo con su acosador. El despertar a la realidad de la vigilia, abrazado a Vera, lo reconforta, y el enunciador fílmico desplaza entonces la atención a ella, partiendo de un primer plano frontal de su rostro dormido que, mediante un encadenado, "extrae" del interior de su mente la imagen de un joven ocupado en vestir a un maniquí femenino tras el cristal de un escaparate. Sutilmente se sugiere ya una relación entre Vera y Vicente -remitiendo a las escenas en que Vera "viste" estatuillas-, a cuya presentación se dedica este breve flashback que lo muestra en el núcleo familiar-afectivo que tanta importancia tendrá en el desenlace. Es un guapo joven, algo pagado de su masculinidad, que trabaja

\footnotetext{
29 No me detengo en las connotaciones de esta violación que supone para Vicente/Vera la primera experiencia y puesta a prueba del nuevo órgano sexual; también la vivencia de lo que significa la posición femenina en el coito y, en el orden patriarcal, una iniciación sexual que "la hace mujer".

${ }^{30}$ Esta pesadilla se inicia con la imagen de la cabeza de Robert adentrándose en la gran boca negra de la trompeta de uno de los músicos de la fiesta.
} 


\section{Carmen Peña Ardid}

en la tienda de ropa de su madre y, a veces, «acosa» a la atractiva empleada Cristina, a la que pretende redimir de su lesbianismo regalándole un vestido para que vaya con él a una fiesta. Cuando se aleja (solo) en su moto, la narración vuelve al presente de la vigilia. Hay un cambio en la postura simétrica de Robert y Vera, que, como un Jano bifronte, duermen ahora mirando a lados opuestos de la cama. Un suave movimiento de cámara hace surgir junto a Vera -compartiendo el encuadre- el rostro de Vicente, en la boda, que se gira como si la mirarse y gana nitidez como si cobrara fuerza desde el pasado lo oculto y reprimido. Es un recurso de gran riqueza expresiva que anticipa la complejidad del enigma identitario ${ }^{31}$ como ocurre en la novela con el inesperado cambio de género gramatical que distingue el pasado-masculino (Vincent) y el presente-femenino (Ève).

Este tercer flashback es el más prolongado. Retoma escenas ya vistas de la boda de doña Casilda donde Norma y Vicente entablan una relación equívoca, pues el joven ignora que ella está en tratamiento psiquiátrico. Vicente no es un agresor brutal como Vincent y, sobre todo, Alex. El filme muestra su inconsciencia y falta de empatía. Su deseo es la única medida del encuentro sexual e interpreta el contento de la joven con sus caricias como la aceptación natural del coito. Cuando intenta penetrarla, suena la canción Pelo amor de amar, que Norma asocia al trauma de la muerte de su madre, y la joven rechaza el peso de su cuerpo, grita, le muerde y recibe a cambio un golpe que la deja inconsciente. Robert Ledgard solo ve huir en la moto al hombre que ha devuelto a su hija a un estado de enajenación mental. A partir de ahora se desarrollan, próximas a la novela, las escenas de búsqueda, captura y encierro del violador -al que Almodóvar concede la dignidad de «Prometeo encadenado» (2012:95)-, que alternan con las visitas del doctor al centro de neuropsiquiatría en el que permanece Norma hasta su suicidio. El día del entierro, con su antiguo equipo de colaboradores, Ledgard practica a Vicente una operación que solo cuando él lo pregunta sabremos que es «una vaginoplastia».

En el filme, la revelación de que detrás de la persona de Vera está Vicente exige al espectador/a reinterpretar lo ya visto, modular la valoración previa de los personajes - ajustada a otras razones o culpas- y dar nuevo sentido a sucesos que pierden su carácter convencional al afectar a un sujeto "no del todo" femenino (la cautividad, la violación, el voyeurismo). Se ofrece ahora la descripción -alusiva- de las etapas del proceso de reasignación sexual (de varón a mujer), incidiendo solo en el resultado de las operaciones quirúrgicas (la mamoplastia, la ablación de la

\footnotetext{
31 Está ligado al uso de la "imagen translúcida” y a herramientas fílmicas distorsionadoras como el fuera de foco o el montaje encadenado. Como ha estudiado bien José Enrique Mora, cuando el cineasta manchego la emplea «suele aludir al universo del secreto, de lo oculto y oscuro, del fantasma, de aquello que ha sido reprimido o no debe ser nombrado. En concreto, lo encontramos con frecuencia asociado a las grietas del género...» (2016: 429).
} 
nuez...) para poner en escena -o dejar fuera de la escena- las situaciones de mayor fuerza simbólica. Tras el afeitado/castrador de Vicente y su despertar en el quirófano, no vemos lo que él ve al mirar sus órganos sexuales en el cristal de una puerta, pero sí la desolación de su mirada cuando Ledgard le muestra el juego de penes-dilatadores de distintos tamaños que debe usar para mantener la elasticidad de la nueva vagina. El plano en el que su rostro queda cubierto por ellos no solo constata que el órgano viril que antes poseía está fuera de él, sino que, en la economía heterosexual del deseo, ha de aprender a "someterse" a esos penes extraños que se disponen sobre su faz como los barrotes de una cárcel $^{32}$. A pesar del trauma, Vicente pregunta si puede irse «a su casa» y la respuesta de Ledgard («Solo estamos empezando») anuncia la etapa más tortuosa del proceso de metamorfosis que exige cubrir su cuerpo con un body y el rostro con una máscara. Pero pocas veces se muestra como una criatura dócil e interiormente sometida. Antes de que Ledgard la bautice con el nombre de «Vera», ya ha intentado huir y suicidarse. Y el bautismo no merma su rebeldía ni la resistencia a asumir un género (una piel) que no reconoce como propio y que además de vestidos y maquillaje también significa violación.

\subsection{Vicente Guillén / Vera (Cruz): el libre albedrío y la identidad de género}

La diferencia más profunda de La piel que habito con la novela de Jonquet tiene que ver con la concepción del personaje cuyo nombre -Vincent/Vicente- no cambia. Vimos que en Tarántula, la culminación del proceso de cambio de sexo es vivida por Vincent como una muerte personal y social de su identidad anterior. Es más, incluso cuando expresa agresivamente rechazo y odio (al interpretar al piano la canción que más hace sufrir a Richard o al pintar un grotesco retrato que lo muestra como un travestí sentado ante la barra de un bar, con ligueros y zapatos de tacón alto), su mundo gira en torno a «Tarántula» y, junto a él, le llega la posibilidad de redención. No ocurre así en La piel que habito, donde Vicente Guillén - cuya culpa es más "leve"-sobrevive construyéndose un mundo propio guiado por la práctica del yoga, la lectura y la inspiración de Louise Bourgeois, convertida en luz de su encierro. La convicción con que emprende la escritura del diario mural -un diálogo interior traducido en palotes, dibujos y lemas verbales repetidos- da testimonio tanto de la voluntad de vivir como de una persistencia en la memoria del propio yo. La oportunidad de salvarse le llega, en un orden fuertemente patriarcal, adoptando la máscara femenina que ha descubierto que Ledgard ama. Y las huellas del pasado vienen en su ayuda. Cuando Vera sale de la mansión por

\footnotetext{
32 La escena subraya la visión faloesencialista de la masculinidad (y del poder que, como el falo, sigue poseyendo el doctor) y el coitocentrismo como práctica heterosexual.
} 


\section{Carmen Peña Ardid}

primera vez con Marilia para ir de compras, reconocemos, a su regreso, el vestido que quiso regalar a Cristina antes de su desaparición. También el azar pone a su alcance la fotografía de Vicente Guillén publicada en el periódico que lleva a la casa de Ledgard uno de sus colegas. Se reconoce en él con un beso porque Vicente permanece en Vera, y esa misma noche huye de la mansión de la única forma posible, dando muerte a Richard y a Marilia. Con este desenlace (justiciero), Almodóvar pone énfasis en el derecho a la libertad y a la venganza por un castigo desmesurado ${ }^{33}$. Y enfrenta a su personaje con otro dilema esencial: el de volver al hogar y hacerse reconocer por los suyos desde su apariencia femenina. Vicente ha salvaguardado durante seis años una identidad masculina fundada en la memoria y en un mundo afectivo al que volver. Lo pone a prueba cuando, en la tienda materna, declara ante Cristina y luego ante su madre: «Soy Vicente», luciendo el vestido que sirve a la anagnórisis, a la vez que revela la magnitud de su drama. De este modo pone de manifiesto igualmente que no va a vivir en su nueva piel de una forma coherente (como Éve en la novela), sino contradictoria, de acuerdo con la matriz normativa de la identidad sexo/género. El programa impuesto por el Ledgard-Pigmalión ha fracasado o se ha vuelto más complejo, pues Vicente no va a «respirar por la vagina»; vivirá con un sexo biológico femenino, una identidad de género masculina y una orientación sexual probablemente hetero-lesbiana.

\subsection{Lo femenino, ¿un ámbito vacío de identidad?}

Partiendo de la novela de Jonquet, La piel que habito propone, entre otros temas, una reflexión sobre la cárcel que representa para algunos seres el cuerpo "equivocado" en el que han nacido. La experiencia extremada que vive el protagonista ilustra sobre las violencias del poder (hetero)patriarcal y allana el camino para entender que no es monstruosa la separación entre la identidad de género, la verdad del cuerpo y la orientación del deseo sexual. Pero algunas lecturas del filme han puesto el acento en su (supuesta) visión del cuerpo como algo inacabado en constante redefinición y en el apoyo a una identidad de género «flexible, inestable y fluida» (Coelho/Gonzaga, 2013: 77-78). También Barbara Zecchi sostiene que, en el desenlace, «tres mujeres unidas por lazos afectivos profundos -la madre, la empleada lesbiana y la mujer transgénero- anticipan la configuración de un universo inclusivo queer que prescinde de categorizaciones y que desestabiliza nociones de normalidad y sexualidad» (2015: 50) ${ }^{34}$. La pregunta que surge entonces es cómo

\footnotetext{
${ }^{33}$ Cabe poner en parangón el desenlace por el que optó Buñuel en Tristana, cuando ella deja morir a Don Lope en lugar de vivir mutilada y "felizmente" casada con un viejo, como en la novela de Galdós.

${ }^{34}$ Es inexacto considerar una «mujer transgénero» a quien cambia de sexo por imposición y quiere seguir llamándose "Vicente" (sobre las disimetrías en la transexualidad masculina y femenina, véase Garber, 1994).
} 
entender que el escenario de la metamorfosis, la manipulación, la espectacularización $\mathrm{y} / \mathrm{o}$ violación siga siendo únicamente el cuerpo femenino (el de Vera/Elena Anaya); por qué lo flexible y fluido solo tiene - de momento- cuerpo de mujer y por qué solo la feminidad deviene como un concepto vacío o incluso el punto de acogida para desheredados de la norma heteropatriarcal. ¿Cómo representar la «fluidez identitaria» (Russo, 2019: 180) imaginando el devenir varón? ¿Es realmente posible desestabilizar la norma de sexo/género imperante sin tocar el ser varón, privilegio con el que se nace?

\section{Bibliografía CitAda}

Almodóvar, Pedro (2012), "Comentarios del autor», en La piel que habito, Barcelona, Anagrama.

ARONICA, Daniela (2005), «Intertextualidad y autorreferencialidad: Almodóvar y el cine español», en F. A. Zurian Hernández y Carmen Vázquez Varela (coords.), Almodóvar. El cine como pasión, Ediciones de la Universidad de Castilla-La Mancha, págs. 57-80.

ATwOOD, Margaret (2006), La maldición de Eva, Barcelona, Lumen.

BOYERO, Carlos (2011), «Retrato de un horror aún más hueco que frío», El País, 20/05, s. pág. [En línea: https://elpais.com/diario/2011/05/20/cultura/1305842401_8502 15.html. Fecha de consulta: 12/03/2020].

Cabello Ruiz, María Teresa (2014), «Intertextualidad en La piel que habito: Louise Bourgeois según Pedro Almodóvar», Sesión no numerada, 4, págs. 34-46.

CAmero PÉreZ, Carmen (2011), «Desdoblamiento y transformación de la identidad del personaje en Mygale de Thierry Jonquet», Çédille. Revista de estudios franceses, 2, págs. 231-252.

Coelho, Paloma y Jayme Gonzaga (2013), «Gênero, corpo e sexualidade em Tudo sobre mina mäe e $A$ pele que habito, de Pedro Almodóvar», Revista Latinoamericana de Estudios sobre Cuerpos, Emociones y Sociedad, 11, págs. 71-82.

DargIS, Manohla (2011), «The Skin I Live In», The New York Times, 13/10, s. pág. [En línea: https://www.nytimes.com/2011/10/14/movies/theskin-i-live-in-directed-by-pedro-almodovar-review.html. Fecha de consulta: 22/05/2020].

EISENSTEIN, Sergei (1982 [1933]), «Cine y literatura (Sobre lo metafórico)», en Cinematismo, Buenos Aires, Quetzal.

FERNÁNDEZ, Luis Miguel (2003), «La recreación fílmica como encrucijada de textos y como fenómeno histórico», en J. A. Pérez Bowie (ed.), La adaptación cinematográfica de textos literarios. Teoría y práctica, Salamanca, Plaza Universitaria Ediciones, págs. 57-65.

Garber, Majorie (1994), «Spare Parts: The Surgical Construction of Gender», en A. C. Herrmann y A. J. Stewart (eds.), Theorizing 


\section{Carmen Peña Ardid}

Feminism. Parallel Trends in the Humanities and Social Sciences, San Francisco/Oxford, Westview Press, págs. 238-256.

GASCÓN-VerA, Elena (2014), «La mujer desencializada en La piel que habito (2011) de Pedro Almodóvar», en F. Serra de Renobales y H. Talaya Manso (eds.), Agentes de cambio. Perspectivas cinematográficas de España y Latinoamérica en el siglo XXI, Madrid, Pliegos, págs. 55-62.

Herrero Cecilia, Juan (2011), «Thierry Jonquet, maestro de la novela negra», Çédille. Revista de estudios franceses, 7, págs. 350-356.

JONQUET, Thierry (2007 [1984]), Tarántula, Barcelona, Ediciones B.

Jung, Dongsup (2014), «Yuxtaposición artística en La piel que habito de Pedro Almodóvar: en torno a las obras de Tiziano, Louise Bourgeois, Guillermo Pérez Villalta y Juan Gatti», Neophilologus, 98, págs. 617-635. JUNKERJÜRGEN, Ralf (2018), «La peli que habito: Intermedialidad entre el arte, la auto-reflexión y el "product placement" en la obra de Almodóvar», Bulletin of Hispanic Studies, 95/1, págs. 61-74.

MARTín, Annabel (2014), «Gendered Logics of Violence: Skin and Cloth, Sutures and Memory Pedro Almodóvar's The Skin I Live In (2011)», Miríada Hispánica, 8, págs. 109-133.

Molina FoIx, Vicente (2012), «Prólogo: El laboratorio del doctor Almodóvar», en $\mathrm{P}$. Almodóvar, La piel que habito, Barcelona, Anagrama, págs. 7-12.

Mora DíEZ, José Enrique (2016), «La memoria translúcida. Opacidad y transparencia de la imagen en el cine de Pedro Almodóvar (19801999)», en P. Peyraga, M. Gautreau, C. Peña Ardid y K. Sojo (eds.), La imagen translúcida en los mundos hispánicos, Villeurbanne, Éditions Orbis Tertius, págs. 415-437.

Morata, Rafael (2017), «La piel que habito (Pedro Almodovar, 2011)», El cine por delante, $17 / 4$, s. pág. [En línea: https: / / rafamorata.es/elcinepordelante/la-piel-que-habito-pedroalmodovar-2011/. Fecha de consulta: 14/04/2020].

Mucha, Márcia (2016), «Do grotesco ao sublime: a violência como elemento condicionante de redenção em Tarântula, de Thierry Jonquet», Revista Porto das Letras, 2, págs.123-134.

Nead, Lynda (1998), El desnudo femenino. Arte, obscenidad y sexualidad, Madrid, Tecnos.

PARÉS Pulido, Marina (2014), «Intertextualidad en La piel que habito: pintura, escultura y dibujo», Fotocinema, 4, págs.325-360.

Pedraza, Pilar (1998), Máquinas de amar. Secretos del cuerpo artificial, Madrid, Valdemar.

PEÑA ARDID, Carmen (2004), «De la resignación a la ira: el punto de vista de las mujeres en el cine de Luis Buñuel», en I. Santaolalla (coord.), Buñuel, siglo XXI, Zaragoza, Prensas de la Universidad de Zaragoza, págs. 369-378.

PEÑa ARDID, Carmen, (2014), «Défis culturels et théoriques du lien entre la littérature et le cinema: l'adaptation d'oeuvres littéraires», en A. 
Louati (ed.), Fiction littérarie et le cinéma.Constantes et mutations d'une interrelation das le monde contemporain, Carthage, Académie Tunisienne des Sciences, des Letres et des Arts Beït al-Hikma, págs. 199-211.

Poyato SÁncheZ, Pedro (2015), «Programas iconográficos en la piel que habito (Almodóvar, 2011)», Anales de Historia del Arte, 25, págs. 283-302.

Preciado, Beatriz (2011), Manifiesto contrasexual, Barcelona, Anagrama.

Rodrígues Albes, Maria Cláudia y Maria Celeste Tomasello (2013), «Intertextualidades, símbolos e mitos entre o romance Mygale e o filme $A$ pele que habito», Cuaderno Seminal Digital, 20, págs. 137-161.

Russo, Michela (2019), «Devolver la mirada: el personaje de Vera en La piel que habito de Pedro Almodóvar», Comunicación y género, 2/2, págs. 161-182 [En línea: https://doi.org/10.5209/cgen.66508. Fecha de consulta: 12/03/2020].

SÁNCHEZ NORIEGA, José Luis (2017), Universo Almodóvar. Estética de la pasión en un cineasta posmoderno, Madrid, Alianza.

Seguin, Jean-Claude (2009), Pedro Almodóvar o la deriva de los cuerpos, Murcia, Tres Fronteras Ediciones.

SMITH, Paul Julian (2011), «La piel que habito (The Skin I Live In, 2011). Stitches in Time», en Desire Unlimited. The cinema of Pedro Almodóvar, London, Verso, págs. 201-207.

SOTINEL, Thomas (2011), «La piel que habito: l'éblouissante expérience du docteur Almodóvar», Le Monde, 14/04, s. pág. [En línea: https://www.lemonde.fr/festival-de-cannes/article/2011/04/14/lapiel-que-habito-de-pedro-almodovar_1507901_766360.html. Fecha de consulta: 12/03/2020].

Thibaudeau, Pascale (2012), «El cuerpo, la piel y la pantalla: los territorios habitados por Pedro Almodóvar», Fotocinema, 7, págs. 192-208.

ZeCCHI, Barbara (2015), «El cine de Pedro Almodóvar: de lo óptico a lo háptico, de Gay a "New Queer”», Área abierta, 15/1, págs. 31-52.

Zurian, Francisco (2013), «La piel que habito. A Story of Imposed Gender and the Struggle for Identity», en M. D’Lugo y K. M. Vernon (eds.), A Companion to Pedro Almodóvar, Malden, John Wiley \& Sons, págs. 262-278.

Fecha de recepción: 27/07/2020.

Fecha de aceptación: 31/07/2020. 